\title{
Influence of mild alkaline treatment on the cellulosic surfaces active sites
}

\author{
Alireza Ashori ${ }^{\mathrm{a}, *}$, Mariana Ornelas $^{\mathrm{b}}$, Shabnam Sheshmani ${ }^{\mathrm{c}}$, Nereida Cordeiro $^{\mathrm{b}}$ \\ a Department of Chemical Technologies, Iranian Research Organization for Science and Technology (IROST), Tehran, Iran \\ ${ }^{\mathrm{b}}$ Competence Center in Exact Science and Engineering, University of Madeira, Funchal, Portugal \\ ${ }^{\mathrm{c}}$ Department of Chemistry, Shahr-e-Rey Branch, Islamic Azad University, Tehran, Iran
}

\section{A R T I C L E I N F O}

\section{Article history:}

Received 27 December 2011

Received in revised form 19 January 2012

Accepted 4 February 2012

Available online 10 February 2012

\section{Keywords:}

Agro-residues fibers

Alkaline treatment

Inverse gas chromatography

Surface properties

\begin{abstract}
A B S T R A C T
Agro-residues fibers are inexpensive environmentally friendly alternatives to synthetic fibers in fiberreinforced polymer composites. The natural fiber properties and bondability with adhesive can be modified by subjecting the fibers to a pre-treatment procedure. The knowledge of the modified fibers surface properties is essential to explain and predict their applications. The present study is focused on the effect of alkaline treatment on the surface characteristics of stalk fibers from rapeseed, tobacco, cotton, lemon balm and kiwi. The chemical composition of fibers and Fourier transform infrared spectroscopy show components extraction and the X-ray diffraction show improvement in the crystallinity index of the treated fibers. But only the IGC analysis allows us to know in detail the alterations on the fiber surface and the effect on the adhesion of the fibers. IGC shows that alkaline treatment produces changes in the nature and number of the active sites, responsible for the physico-chemical activity of the surface of the fibers. The fiber hydrophobicity was improved by the increase of more energetic and active sites in the surface. Also, the creation of new basic active sites and removal of acidic active sites from the fiber surface due to alkaline treatment has been clearly shown.
\end{abstract}

(C) 2012 Elsevier Ltd. All rights reserved.

\section{Introduction}

In the last 20 years, plant fibers extracted from biomass are experiencing increased demand as reinforcing materials for polymer matrices. Applications of fiber-reinforced composites have diversified into products such as building materials and structural parts for motor vehicles by replacing the petroleum derived conventional reinforcing materials (Ashori, 2008; Panthapulakkal, Zereshkian, \& Sain, 2006). The extensive use of lignocellulosic fibers and their composites is because of their properties such as low density, high specific properties, non-abrasive nature, high level of filler loadings, availability, renewability, safe working environment, as well as other properties (Tabarsa, Ashori, \& Golamzadeh, 2011).

The composite industry always looks into alternative low cost lignocellulosic sources, which can decrease overall manufacturing costs and increase stiffness of the materials. In addition to wood based fibers, several types of agro-residues fibers have been used for making both thermoplastic and thermoset composites. Field crop residues and/or agricultural by-products such as cereal straw, corn stalks, flax straw, corn cob, rice husk, and bagasse represent potentially valuable sources of fiber, which could be used as supplements or as direct substitutes for wood fiber and

\footnotetext{
* Corresponding author. Tel.: +98 21 56275192; fax: +98 2156275191.

E-mail address: ashori@irost.org (A. Ashori).
}

in the manufacture of composites (Panthapulakkal \& Sain, 2007). The abundant availability of these inexpensive residues makes the refining of agro-residues acceptable for the production of high value fiber composites. Throughout the world, tons of unused agroresidues are generated every year, and only a small percentage has been used for applications such as feedstock and energy production. Use of agro-residues as fillers or reinforcements in the production of plastic composites alleviate the shortage of wood resources and can have the potential to start a natural fiber industry in countries where there are little or no wood resources left. In addition, use of these agricultural crop residues could open up new markets and improve the rural agriculture based economies (Nourbakhsh \& Ashori, 2010).

In general, the mechanical performances of a composite with plant (wood and non-wood) fibers strongly depend on the nature of the fibers and principally on the quality of the adhesion matrix/fibers. To improve the adhesion matrix/fibers, the natural fibers usually require a pre-treatment before they can be incorporated in composites to ensure a minimum level of product quality. Alkaline treatment is a usual method employed for improving the surface properties of fibers (Sheshmani, Ashori, \& Farhani, 2012). It is important to note that the behavior of natural fibers will be conditioned by the extent of its surface properties. Consequently, the knowledge of the modification of the surface properties (chemical surface, morphological surface and energy surface) of fibers is essential to explain and predict the applications of these fibers. 
The present work is based on the valorization of different agroresidues fibers. The alkaline treatment was applied, and chemical compositions, Fourier transform infrared (FTIR) and X-ray diffractometry (XDR) were used to characterize the changes in the fibers. Particular attention was given to surface alterations, namely to the surface properties which were evaluated by Inverse gas chromatography (IGC). IGC is a well-established technique for the determination of the surface properties, including dispersive (London) and specific interactions, at the molecular level. It has been proved that this technique is very effective for the surface characterization of various materials, including lignocellulosic materials (Ren \& Buschle-Diller, 2007; Abdelmouleh et al., 2004; Belgacem \& Gandini, 1999; Cantergiani \& Benczédi, 2002; Cordeiro et al., 2007; Cordeiro, Neto, Gandini, \& Belgacem, 1995). This technique reflects the interaction between the isolated probe molecule and the solid surface, and consists of the injection of negligible quantities of probes molecules (vapor) with known properties. IGC provides access to many parameters. In this paper, IGC is used to determine the dispersive component of surface energy, specific free energy of adsorption, acid-base surface character, specific surface area, monolayer capacity and the distribution functions of the adsorption energy sites on the solid surface of 5 agro-residues fibers.

\section{Experimental procedures}

\subsection{Lignocellulosic materials}

All the fibers studied were from the stalks of rapeseed (Brassica napus), tobacco (Nicotiana tabacum), cotton (Gossypium hirsutum), lemon balm (Melissa officinalis) and kiwi (Actinidia sinensis), taken from the southern and northern parts of Iran. All the raw materials were taken from one harvest, to ensure that, as far as possible, variations in raw materials used were kept to a minimum. The samples were air-dried and ground into a fine "meal" using a Wiley mill. The ground meals were screened and the particles retained at BS 60 mesh $(250 \mu \mathrm{m})$ sieve screen were used for chemical treatment. The chemical compositions of used fibers were done following the standards outlined in the Technical Association of the Pulp and Paper Industry (TAPPI test methods, 2002) and the other published procedures. The samples were chemically characterized in terms of $\alpha$-cellulose (T $203 \mathrm{~cm}-99$ ), Klason lignin (T 222 om-02), holocellulose (Wise \& Karl, 1962), and 1\% NaOH solubility (T 212 om-98). The results presented are the mean and standard deviations of three replicate determinations of each sample.

\subsection{Chemical treatment}

The used stalks fibers were subjected to a soft alkaline treatment with $1 \% \mathrm{NaOH}$ to improve the surface proprieties. The details of the experimental procedure and sample preparations have been reported elsewhere (Cordeiro, Gouveia, \& Jacob John, 2011).

\subsection{Spectroscopic characterization}

The samples before and after chemical treatment were characterized by spectroscopic methods, namely, inverse gas chromatography (IGC), Fourier transform infrared (FTIR), and X-rays diffractometry (XDR).

\subsubsection{IGC}

IGC measurements were carried out using a commercial inverse gas chromatograph (Surface Measurements Systems, London, UK), equipped with a flame ionization detector (FID) and a thermal conductivity detector (TCD). The IGC system is fully automatic with SMS IGC Controller V 1.8 Control Software. Data was analyzed using IGC Standard Analysis Suite V 1.3 and IGC Advanced Analysis Suite
V 1.21. The calculation methodology is described exhaustively by Cordeiro, Gouveia, Moraes, and Amico (2011).

About $1 \mathrm{~g}$ of each sample (raw and treated), with granulometry lower than 40 mesh, was packed in standard glass silanized (dymethyldichlorosilane; Repelcote BDH, UK) columns, with $6 \mathrm{~mm}$ $\mathrm{OD}, 300 \mathrm{~mm}$ length and an internal diameter of $4 \mathrm{~mm}$. The samples were packed by vertical tapping for $2 \mathrm{~h}$, using the SMS sample packing device. The columns with the fibers were conditioned overnight at $333 \mathrm{~K}$ and $10 \mathrm{ml} / \mathrm{min}$ of helium flow rate, and then conditioned for $2 \mathrm{~h}$ at the temperature of analyses and $0 \%$ relatively humidity. After conditioning the columns, pulse injections were carried out with $0.25 \mathrm{ml}$ gas loop. Methane was the tracer molecule used to calculate the dead time.

Five $n$-alkanes (hexane, heptane, octane, nonane and decane) were used to measure the dispersive component of the surface energy at four different temperatures: 293, 296, 298, and $300 \mathrm{~K}$. Four polar probes: tetrahydrofuran, ethyl acetate, ethanol, and acetonitrile were used at the same conditions, to study Gibbs specific free energy and acid-base surface character. The permeability and the isotherm experiments were done using the n-octane as the probe molecule at $298 \mathrm{~K}$. All the experiments were performed at $0 \% \mathrm{RH}$. The experiments were done in duplicate and the presented results are the average values. The experimental error due to the temperature variation, flow rate and retention time measurement was estimated to be below $3.2 \%$.

IGC measurements were carried out on the samples using several non-polar and polar molecules, all being of GC grade (>99\% purity) supplied by Sigma-Aldrich. The methane, used as a noninteracting reference probe, and the carrier gas, helium, had the high purity (>99.99\%) and were supplied by Air Liquide Company.

\subsubsection{FTIR}

FTIR spectra were carried out in a Tensor ${ }^{\mathrm{TM}} 27$, Bruker Optics, Billerica, with a resolution of $4 \mathrm{~cm}^{-1}$ and a scan number equal to 32 . The spectral study was extended over the range $4000-400 \mathrm{~cm}^{-1}$. All spectroscopic measurements were performed for the dried pulverous samples mixing with $\mathrm{KBr}$ (sample/ $\mathrm{KBr}$ ratio, 6/94).

\subsection{3. $X R D$}

X-ray patterns were obtained with a PHILIPS X-ray diffractometer model PW 1800 with a $\mathrm{Cu} K \alpha$ radiation at $30 \mathrm{kV}$ and $17.5 \mathrm{~mA}$. A step size of $0.02^{\circ}$ and a step scan of $2.5 \mathrm{~s}$ were used for the entire reading range $\left(4-60^{\circ}\right)$. The degree of crystallinity was expressed by the crystallinity index $(\mathrm{CI})$, using the method developed by Segal, Creely, Martin, and Conrad (1959) that has been widely applied in the study of natural fibers (Cordeiro, Ornelas, Ashori, Sheshmani, \& Norouzi, 2012).

\section{Results and discussion}

The effect of alkaline treatment on the surface proprieties was exhaustively studied by IGC analysis. Depending on the injected probes, different parameters were determined for the raw and alkaline treated fibers. Using $n$-alkanes probes, the dispersive component of surface energy $\left(\gamma_{S}^{\mathrm{D}}\right)$, the isotherm experiments (monolayer capacity, $n_{m}$, and the surface area, $S_{\mathrm{BET}}$ ) and surface heterogeneity (energetic profile) were obtained. However, if polar probes are injected, the specific free energy of adsorption $\left(\Delta G_{\mathrm{ads}}^{\mathrm{sp}}\right)$ and acid-base surface character ( $K_{a}$ and $K_{b}$ constants) were obtained. These parameters are correlated with the chemical modifications given by the chemical composition, FTIR and X-ray analysis.

The injection of the $n$-alkanes series probes $\left(C_{6}-C_{10}\right)$ allowed the $\gamma_{\mathrm{S}}^{\mathrm{D}}$ determination by the plot of $R T \ln V_{N}$ versus $a\left(\gamma_{\mathrm{L}}^{\mathrm{D}}\right)^{1 / 2}$ (Fig. 1). Excellent linear correlation was obtained (0.9990-0.9996) for all 
Table 1

Dispersive component of the surface tension $\left(\gamma_{S}^{\mathrm{D}}\right)$ and its variation with temperature $\left(\Delta \gamma_{S}^{\mathrm{D}} / \Delta T\right)$ and the crystallinity index $(\mathrm{CI})$ of the raw and treated fibers.

\begin{tabular}{|c|c|c|c|c|c|c|c|}
\hline \multirow[t]{2}{*}{ Fibers } & & \multicolumn{4}{|c|}{$\gamma_{\mathrm{S}}^{\mathrm{D}}\left(\mathrm{mJ} / \mathrm{m}^{2}\right)$} & \multirow[t]{2}{*}{$\left(\Delta \gamma_{\mathrm{S}}^{\mathrm{D}} / \Delta T\right)\left(\mathrm{mJ} \mathrm{m}^{-2} / \mathrm{K}\right)$} & \multirow[t]{2}{*}{$\mathrm{CI}(\%)$} \\
\hline & & $293 \mathrm{~K}$ & $296 \mathrm{~K}$ & $298 \mathrm{~K}$ & $300 \mathrm{~K}$ & & \\
\hline \multirow[t]{2}{*}{ Rapeseed } & Raw & 43.32 & 42.26 & 41.53 & 40.62 & 0.39 & 53.21 \\
\hline & Treated & 44.87 & 44.05 & 43.25 & 42.48 & 0.34 & 53.25 \\
\hline \multirow[t]{2}{*}{ Tobacco } & Raw & 55.96 & 54.24 & 51.78 & 49.95 & 0.86 & 52.86 \\
\hline & Treated & 44.67 & 43.50 & 43.09 & 41.93 & 0.39 & 54.51 \\
\hline \multirow[t]{2}{*}{ Cotton } & Raw & 44.12 & 43.18 & 41.93 & 41.35 & 0.40 & 52.86 \\
\hline & Treated & 41.90 & 41.31 & 40.62 & 39.95 & 0.28 & 59.79 \\
\hline \multirow[t]{2}{*}{ Lemon balm } & Raw & 47.96 & 47.12 & 46.02 & 45.66 & 0.46 & 34.88 \\
\hline & Treated & 47.82 & 46.26 & 45.23 & 44.60 & 0.33 & 45.30 \\
\hline \multirow[t]{2}{*}{ Kiwi } & Raw & 47.30 & 45.85 & 45.23 & 44.32 & 0.43 & 46.75 \\
\hline & Treated & 43.38 & 42.58 & 41.81 & 41.06 & 0.33 & 53.46 \\
\hline
\end{tabular}

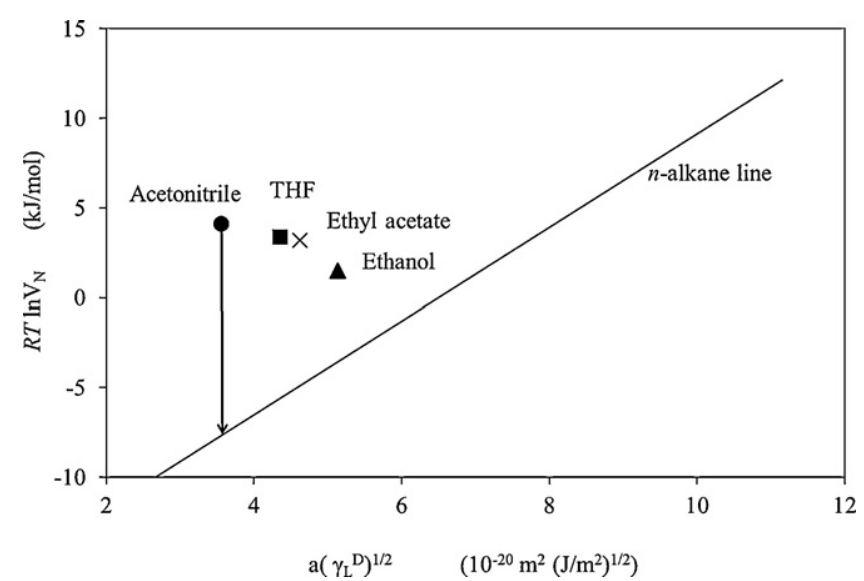

Fig. 1. Plot of $R T \ln V_{N}$ versus $a\left(\gamma_{\mathrm{L}}^{\mathrm{D}}\right)^{1 / 2}$ for $n$-alkanes and polar probes onto cotton fibers before alkaline treatment.

the stalk fibers under study (rapeseed, tobacco, cotton, lemon balm and kiwi). The calculated $\gamma_{\mathrm{S}}^{\mathrm{D}}$ are gathered in Table 1 . Tobacco presented the highest value of the $\gamma_{S}^{\mathrm{D}}\left(51.78 \mathrm{~mJ} / \mathrm{m}^{2}\right.$, at $\left.298 \mathrm{~K}\right)$, while cotton and rapeseed exhibited the lowest values of $\gamma_{\mathrm{S}}^{\mathrm{D}}\left(42 \mathrm{~mJ} / \mathrm{m}^{2}\right.$, at $298 \mathrm{~K}$ ). These values are close to those reported in the literature for similar materials (Cordeiro, Gouveia, Moraes, et al., 2011; Cordeiro, Ornelas, et al., 2012; Mills, Gardner, \& Wimmer, 2008).

Mills et al. (2008) associate the $\gamma_{S}^{\mathrm{D}}$ increase with lignin decrease and cellulose increase content of the analyzed material. In present study, this relationship is not observed (Fig. 2). The different origin

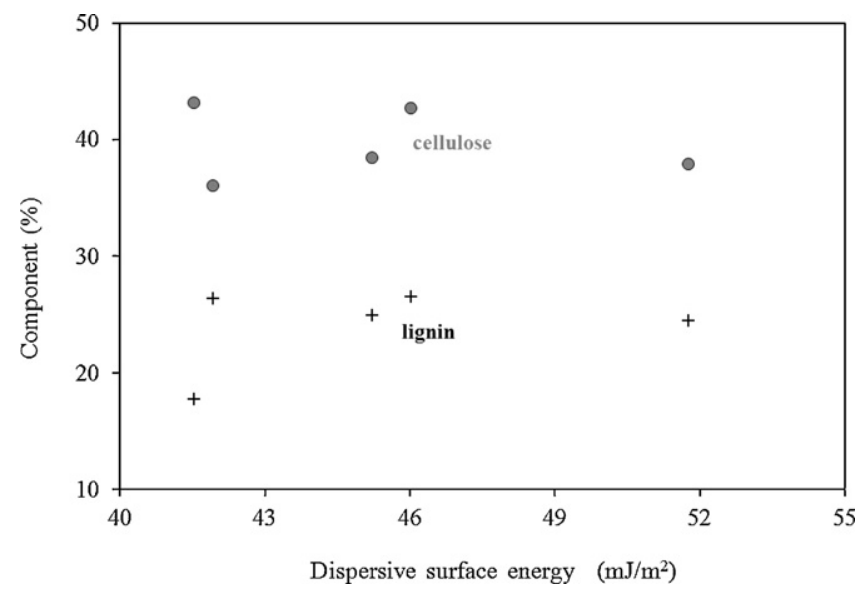

Fig. 2. Variation of the dispersive component of surface energy with cellulose and lignin content in raw fibers. of the fibers, the plant growing conditions, the location from which the fiber is removed in the plant, the components arrangement, can justify this absence of correlation between $\gamma_{S}^{\mathrm{D}}$ and the content of the two major fibers constituents (cellulose and lignin).

The used stalk fibers were subjected to a soft alkaline treatment to improve the surface proprieties. A significant amount of fibers components was extracted (Table 2 ), with the higher amount extracted for the lemon balm, $68.9 \%$, compared to the $c a .40 \%$ for the other fibers. This extract can be constituted by waxes, oils, monossacarideos, free aromatics and other small components. In some cases, also lignin, hemicellulose and pectin can be extracted (Cordeiro, Mendonça, Pothan, \& Varma, 2012; Le Troedec et al., 2008). The extraction of these components can be observed by analysing the FTIR spectrum. The spectra of kiwi stalk fibers, before and after alkaline treatment (Fig. 3), exemplified the observed changes for all the fibers. The peaks in the region at $1740 \mathrm{~cm}^{-1}$, in the raw fibers attributed to either the acetyl and uronic ester groups of the hemicelluloses or the ester linkage of carboxylic group of the ferulic and $p$-coumaric acids of lignin (Alemdar \& Sain, 2008; Cherian et al., 2008), disappeared in the spectra of the treated fibers, which indicates a complete cleavage of these ester bonds. The intensity of the peaks attributed to $\mathrm{C}=\mathrm{C}$ of aromatic skeletal vibrations in lignin, in the region of $1500-1600 \mathrm{~cm}^{-1}$, has decreased in treated fibers reflecting partial removal of lignin. Also, the disappearance of the peak around $1260 \mathrm{~cm}^{-1}$ after alkalization indicates the preferential removal of hemicelluloses materials rather than lignin (Mwaikambo \& Ansell, 2002). The alterations in the chemical composition of the fibers are reflected in the surfaces proprieties.

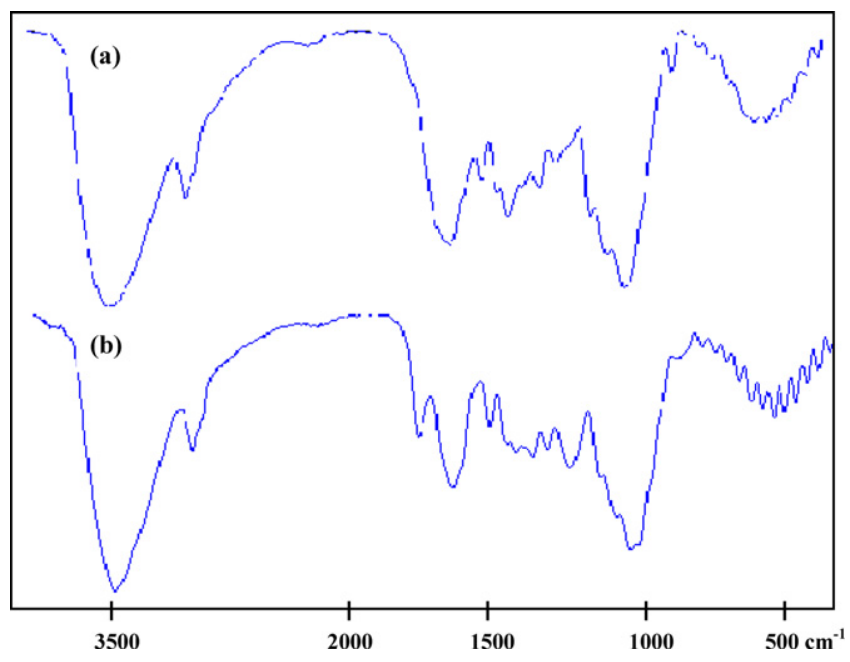

Fig. 3. FTIR spectra of kiwi before (a) and after (b) $\mathrm{NaOH}$ treatment. 
Table 2

Chemical compositions of used raw fibers ( $w / w \%$ of dry material).

\begin{tabular}{|c|c|c|c|c|}
\hline Components & $\alpha$-Cellulose & Hemicellulose & Lignin & $1 \% \mathrm{NaOH}$ solubles \\
\hline Rapeseed & $43.1 \pm 1.6$ & $30.4 \pm 1.8$ & $17.7 \pm 2.2$ & $43.8 \pm 2.6$ \\
\hline Tobacco & $37.9 \pm 4.3$ & $31.2 \pm 3.1$ & $24.5 \pm 3.1$ & $43.5 \pm 4.0$ \\
\hline Cotton & $36.0 \pm 2.2$ & $28.8 \pm 4.4$ & $26.3 \pm 5.2$ & $42.4 \pm 2.8$ \\
\hline Lemon balm & $42.7 \pm 1.8$ & $14.3 \pm 1.3$ & $26.5 \pm 4.3$ & $68.9 \pm 7.5$ \\
\hline Kiwi & $38.4 \pm 2.3$ & $32.6 \pm 2.5$ & $24.9 \pm 2.7$ & $40.4 \pm 3.1$ \\
\hline
\end{tabular}

The calculated $\gamma_{S}^{\mathrm{D}}$ (Table 1) shows tobacco and kiwi as the fibers that present more significant change in the $\gamma_{S}^{\mathrm{D}}$ values due to alkaline treatment-a decreasing is observed. Contrariwise, rapeseed fibers present an increase in the $\gamma_{S}^{\mathrm{D}}$. Lemon balm and cotton fibers also present a decrease in the $\gamma_{S}^{\mathrm{D}}$, but the variation is within the experimental error. Usually, the alkaline treatment removes small and free components, mainly non-polar molecules, decreasing the non-polar active sites of interaction and consequently the $\gamma_{S}^{\mathrm{D}}$. The modifications in the number and/or in the energy of the non-polar active sites in the fibers surface were studied by the energetic profile determined for the $n$-octane. A correlation between $\gamma_{\mathrm{S}}^{\mathrm{D}}$ and the adsorption potential maximum $\left(A_{\max }\right)$ was found for the treated fibers (Fig. 4). The energetic profiles (Fig. 5a) show for all the fibers that the raw fibers present more energetic actives sites $\left(A_{\max }\right.$ $13.07-14.64 \mathrm{~kJ} / \mathrm{mol})$ than treated fibers $\left(A_{\max } 11.14-12.64 \mathrm{~kJ} / \mathrm{mol}\right)$, justifying the decrease of $\gamma_{\mathrm{S}}^{\mathrm{D}}$ with the alkaline treatment. However, rapeseed fibers present a decrease in the $\gamma_{\mathrm{S}}^{\mathrm{D}}$, although the $A_{\max }$ decreases in the treated fibers. This can be justified by the greater number of active sites in the surface (Fig. 5b), which contributes to the increase in $\gamma_{\mathrm{S}}^{\mathrm{D}}$.

The retention of the probes, and consequent IGC data, could be influenced by parameters such as crystallinity and the arrangement or orientation of chemical groups in the surface (Belgacem, Blayo, \& Gandini, 1996; Newell, Buckton, Butler, Thielmann, \& Williams, 2001). The different surface energy reflects different orientations and spacing between the surface molecules, giving rise to the different energy states. The data obtained in our study (Table 1) show that for the same fiber, increase in the $\mathrm{CI}$ decreases $\gamma_{\mathrm{S}}^{\mathrm{D}}$. The relationship between the $\gamma_{S}^{\mathrm{D}}$ and the CI was studied for all the fibers, which shows only a linear correlation with the treated fibers (Fig. 6). The same tendency was observed: $\gamma_{S}^{\mathrm{D}}$ decreases with the increase in CI. Papirer, Brendle, Balard, and Vergelati (2000) found that $\gamma_{\mathrm{S}}^{\mathrm{D}}$ decreases when the crystallinity of cellulose fibers decreases. This apparent disagreement with our results can be due to the fact that the published paper studied "quasi-pure" cellulosic fibers. In our case, the stalk fibers have $\mathrm{CI}$ between 35 and 60\%. Moreover, it is not surprising that the amorphous form gives a higher surface energy

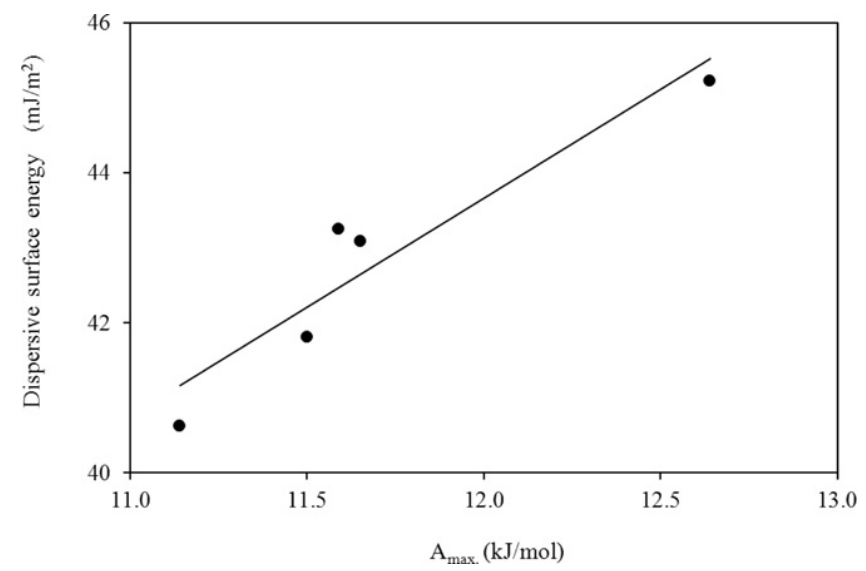

Fig. 4. Variation of the dispersive component of surface energy with adsorption potential maximum $\left(A_{\max }\right)$ onto the fibers after $\mathrm{NaOH}$ treatment.
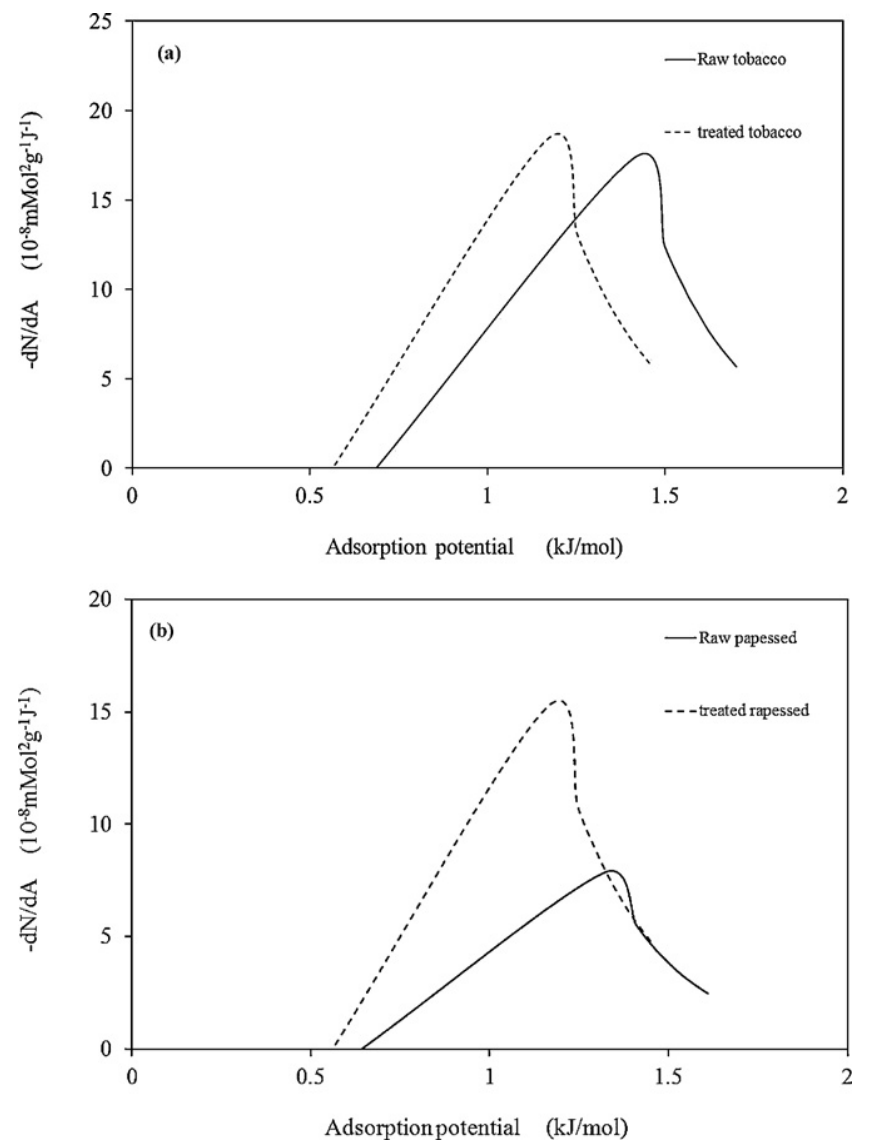

Fig. 5. Heterogeneity profiles for tobacco (a) and rapeseed (b) fibers, before and after alkaline treatment, obtained with $n$-octane at $298 \mathrm{~K}$.

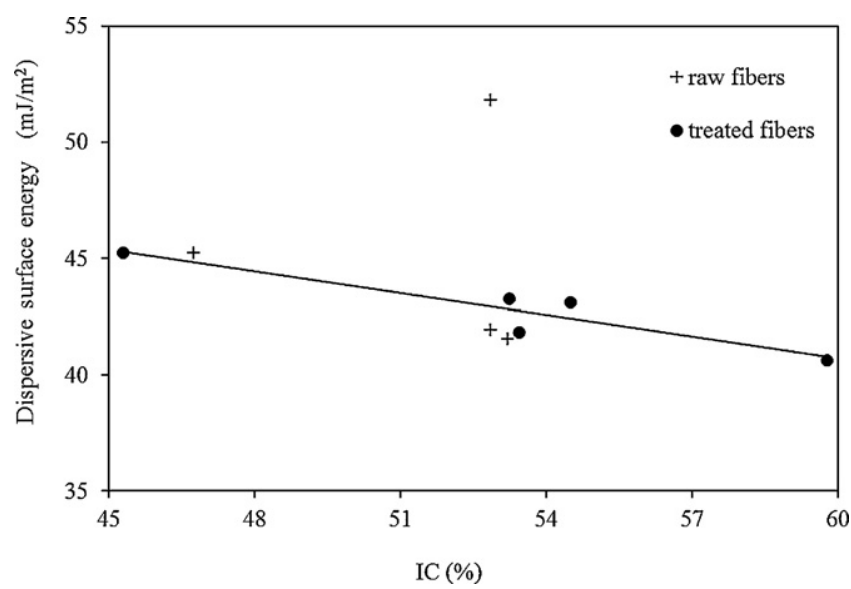

Fig. 6. Variation of the dispersive component of surface energy with the crystallinity index $(\mathrm{CI})$ in the fibers before and after $\mathrm{NaOH}$ treatment. 


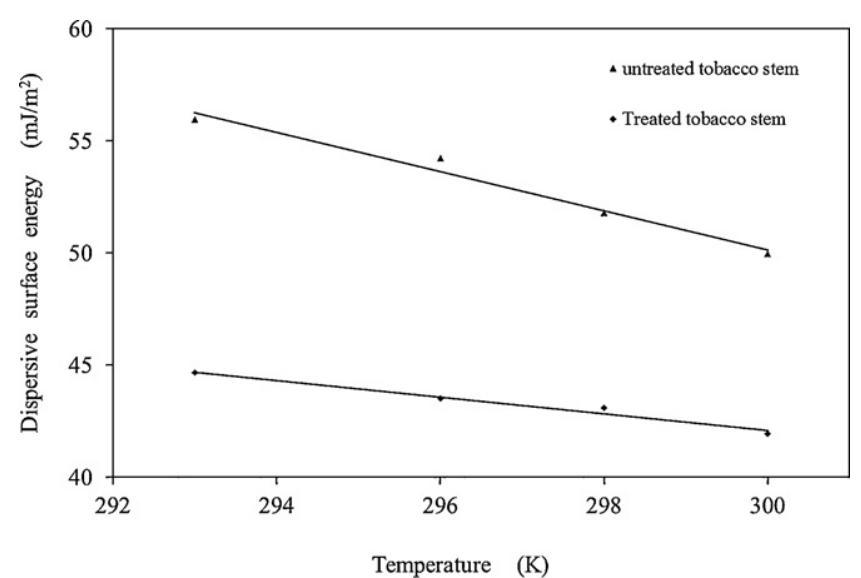

Fig. 7. Variation of the dispersive component of surface energy with temperature for tobacco stalk fibers before and after $\mathrm{NaOH}$ treatment.

than the crystalline form, as the amorphous form is thermodynamically unstable and thus in a higher energy state. Buschle-Diller, Inglesby, and $\mathrm{Wu}(2005)$ observed a decrease of around $6 \mathrm{~mJ} / \mathrm{m}^{2}$ for mercerized cotton. Similar tendency was observed by Cordeiro, Gouveia, Moraes, et al. (2011) for different lignocellulosic fibers: after $4 \% \mathrm{NaOH}$ treatment, the fibers decreased the $\gamma_{\mathrm{S}}^{\mathrm{D}}$ although the $\mathrm{CI}$ increased.

The study of $\gamma_{S}^{\mathrm{D}}$ at different temperatures (293, 296, 298 and $300 \mathrm{~K})$, reported in Table 1, shows for all fibers a linear decrease with the increase in temperature (Fig. 7). The raw fibers present high temperature dependence $\left(0.39-0.89 \mathrm{~mJ} \mathrm{~m}^{-2} / \mathrm{K}\right)$ compared to the treated fibers $\left(0.28-0.39 \mathrm{~mJ} \mathrm{~m}^{-2} / \mathrm{K}\right)$. The decrease with the alkaline treatment can be attributed to the significant removal of small and/or free components from the fibers and to the increase of structural organization presented after treatment, which decreases the entropic factors. This last factor can be partially reflected in the increase of the crystallinity index, observed for all the fibers (Table 1). A remark should be made concerning the rapeseed fibers, in which the alkaline treatment shows a minimum effect on the $\mathrm{CI}$, contrary to the observed behavior for the other fibers.

The injection of polar probes provides the knowledge about the acid-base properties of the fibers surface. The polar probes (acetonitrile, ethyl acetate, ethanol or tetrahydrofuran) are able to exchange dispersive, but also specific interactions with the acid-base groups present in the fibers surface. Therefore, the calculated specific free energy of adsorption, $\Delta G_{\mathrm{ads}}^{\mathrm{sp}}$, shows an increment in the surface interactions (Fig. 1), indicative of acid-base groups in all fibers surfaces. It was observed that the acetonitrile was the polar probe with the higher interaction due to the fact that the acetonitrile is an amphoteric probe and can interact with both acidic and basic groups. The calculated $\Delta G_{\text {ads }}^{\mathrm{sp}}$ was used to predict the surface acidity $\left(K_{a}\right)$ and basicity $\left(K_{b}\right)$. The good coefficient of determination obtained for the linear fitting, shows that the Gutmann's acid-base concept (Gutmann, 1978) is valid for the studied samples and that the specific interactions may be considered of the electron donor-acceptor type. The calculated $K_{a}$ and $K_{b}$, at $298 \mathrm{~K}$ (Table 3), show a slightly predominant basic sites (or electron donor) in the raw fibers surface, with a $K_{b} / K_{a}$ ratio between 1.11 and 1.27 . Exception is found in the cotton fiber that presents a $K_{b} / K_{a}$ ratio of 0.90 . A Lewis basic predominant character was found by other authors for other natural fibers (Cordeiro, Gouveia, Jacob John, et al., 2011; Cordeiro, Gouveia, Moraes, et al., 2011; Mills et al., 2008).

The same polar probes were used in treated fibers and variations in the $\Delta G_{\text {ads }}^{\mathrm{sp}}$ values were observed, which is indicative of modifications in acid and base active sites during the alkaline treatment. A general increase in $\Delta G_{\text {ads }}^{\mathrm{sp}}$ for the acetonitrile was detected,
Table 3

Acid and base constants $\left(K_{a}\right.$ and $\left.K_{b}\right)$ obtained for the raw and treated fibers at $298 \mathrm{~K}$.

\begin{tabular}{lllll}
\hline Fibers & & $K_{a}$ & $K_{b}$ & $K_{b} / K_{a}$ \\
\hline Rapeseed & Raw & 0.09 & 0.10 & 1.11 \\
& Treated & 0.09 & 0.40 & 4.44 \\
Tobacco & Raw & 0.11 & 0.20 & 1.18 \\
& Treated & 0.08 & 0.43 & 5.37 \\
Cotton & Raw & 0.10 & 0.09 & 0.90 \\
& Treated & 0.09 & 0.28 & 3.11 \\
Lemon balm & Raw & 0.10 & 0.12 & 1.2 \\
& Treated & 0.05 & 0.14 & 2.8 \\
Kiwi & Raw & 0.11 & 0.14 & 1.27 \\
& Treated & 0.09 & 0.32 & 3.55 \\
\hline
\end{tabular}

suggesting that alkaline treatment creates new active sites for specific interactions in all fibers. Exception is observed in the lemon balm fiber with a decrease in this parameter, indicative of a decrease in the polar active sites used in the specific interactions. Fig. 8 shows the $\Delta G_{\text {ads }}^{\text {sp }}$ for the ethanol, probe with lower DN/AN* (basic probe), and for tetrahydrofuran, the probe with higher DN/AN* (acid probe). The increase (48-285\%) in $\Delta G_{\text {ads }}^{\mathrm{sp}}$ for the ethanol and the decrease (1.4-52\%) in the $\Delta G_{\text {ads }}^{\text {sp }}$ for the tetrahydrofuran, suggest that the alkaline treatment creates new basic active sites and removes acid active sites from the fiber surfaces. The decrease in $\Delta G_{\mathrm{ads}}^{\mathrm{sp}}$ values for the tetrahydrofuran, for all the fibers, supports the indication given by the FTIR spectra about the extraction of acidic components by alkaline treatment. In terms of acid-base constants, the alkaline treatment increases significantly (133-300\%) the basic character for all fibers. The lemon balm fibers exhibited the lowest ratio of $K_{b} / K_{a}(2.8)$ and the tobacco fiber exhibited the highest ratio of $K_{a} / K_{b}$ (5.37). The increase of basic surface character can be attributed to the more exposed cellulose and hemicelluloses, which presents strong basicity and weak acidity, due to the extractives removal during the alkaline treatment. The modified surface exhibits a rather basic (electron donor) character close to cellulose materials.

To obtain information about the surface area $\left(S_{\mathrm{BET}}\right)$ and the monolayer capacity $\left(n_{m}\right)$ the isotherm experiment was done with the $n$-octane probe. The symmetrical peaks obtained for all the studied fibers were typical of linear adsorption isotherms described by Henry's Law. Using the BET approach, as explained in detail by Condor and Young (1979), the results gathered in Table 4 were obtained. The raw kiwi fibers present the lowest value $\left(0.43 \mathrm{~m}^{2} / \mathrm{g}\right.$ and $\left.1.13 \mu \mathrm{mol} / \mathrm{g}\right)$ and rapeseed present the highest value $\left(1.60 \mathrm{~m}^{2} / \mathrm{g}\right.$ and $\left.4.21 \mu \mathrm{mol} / \mathrm{g}\right)$ of $S_{\mathrm{BET}}$ and $n_{m} . S_{\mathrm{BET}}$ between

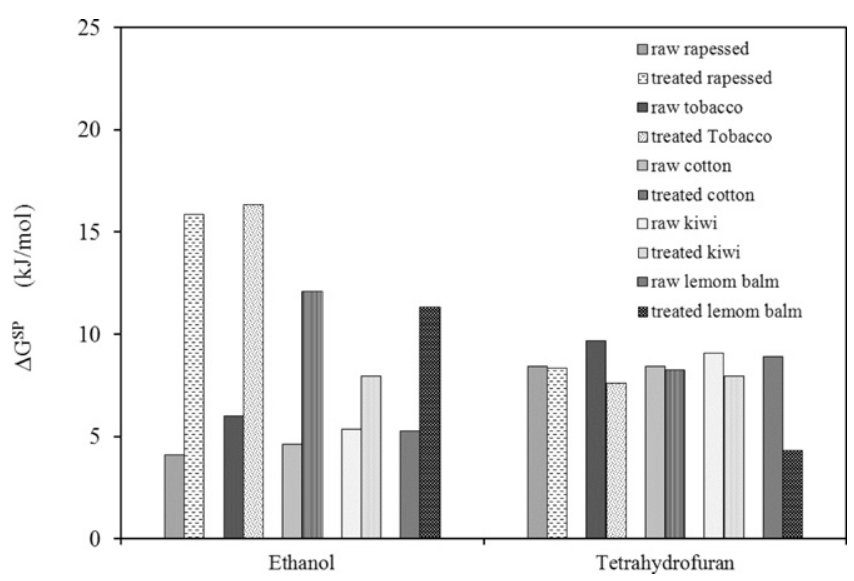

Fig. 8. Specific free energy of adsorption $\left(\Delta G_{\mathrm{ads}}^{\mathrm{sp}}\right)$ obtained the ethanol and tetrahydrofuran probes, onto raw and treated fibers at $298 \mathrm{~K}$. 
Table 4

Adsorption potential distribution maximum $\left(A_{\max }\right)$ specific surface area $\left(S_{\mathrm{BET}}\right)$ and monolayer capacity $\left(n_{m}\right)$ for the raw and treated fibers at $298 \mathrm{~K}$.

\begin{tabular}{lllll}
\hline Fibers & & $A_{\max }(\mathrm{kJ} / \mathrm{mol})$ & $S_{\text {BET }}\left(\mathrm{m}^{2} / \mathrm{g}\right)$ & $n_{m}(\mu \mathrm{mol} / \mathrm{g})$ \\
\hline Rapeseed & Raw & 13.20 & 1.60 & 4.21 \\
& Treated & 11.59 & 0.93 & 2.46 \\
Tobacco & Raw & 14.10 & 0.47 & 1.83 \\
& Treated & 11.65 & 0.69 & 1.23 \\
Cotton & Raw & 13.07 & 0.75 & 1.97 \\
& Treated & 11.14 & 0.84 & 2.21 \\
\multirow{2}{*}{ Lemon balm } & Raw & 14.52 & 0.77 & 2.04 \\
& Treated & 12.64 & 0.80 & 2.10 \\
Kiwi & Raw & 13.53 & 0.43 & 1.13 \\
& Treated & 11.50 & 0.70 & 1.83 \\
\hline
\end{tabular}

0.382 and $2.793 \mathrm{~m}^{2} / \mathrm{g}$ and $n_{m}$ values between 0.3 and $7.4 \mu \mathrm{mol} / \mathrm{g}$ were found by Cordeiro, Mendonça, et al. (2012) for different agromaterials.

In the treated fibers, tobacco fiber has the lowest $\left(0.69 \mathrm{~m}^{2} / \mathrm{g}\right.$ and $1.23 \mu \mathrm{mol} / \mathrm{g})$ and rapeseed has the highest $\left(0.93 \mathrm{~m}^{2} / \mathrm{g}\right.$ and $2.46 \mu \mathrm{mol} / \mathrm{g}$ ) values of $S_{\mathrm{BET}}$ and $n_{m}$. The fibers after alkaline treatment show an increase in the surface area values due to the components extraction with the particle size reduction. An exception is observed in the rapeseed fiber. This result together with the chemical composition, XDR and the surface energy data suggest that the alkaline treatment provokes only alteration in the surface of these fibers, extracting the components and making the surface smoother, which is reflected in a decrease in the surface area.

\section{Conclusions}

The aim of the present study was to determine the effects of alkaline treatment on the surface properties of Iranian cultivated natural fibers that may have impact on their adhesive bond quality. The chemical composition has been considerably affected by the alkaline treatment, producing changes not only in its morphology (increasing the surface area) but also in its surface energy. Indeed, this type of treatment makes possible to produce changes in the nature and number of the active sites in the surface of the fibers. These changes in the surface properties are fundamentally responsible for the physico-chemical activity of the surface of the fibers. The alkaline treatment decreases the $\gamma_{S}^{\mathrm{D}}$, indicating that the fibers became less hydrophobic, but at the same time it also increases remarkably the basic specific interaction of the fibers, causing them to become reactive preferentially with acids couplings agents.

\section{Acknowledgments}

Iranian authors gratefully acknowledge the financial support (grant \# 90001219) from the Iran National Science Foundation (INSF). Portuguese authors would like to thank the "Programa Nacional de Re-equipamento Científico", POCI 2010, by sponsored IGC work (FEDER and Foundation for the Science and Technology).

\section{References}

Abdelmouleh, M., Boufi, S., Belgacem, M. N., Duarte, A. P., Ben Salah, A., \& Gandini, A. (2004). Modification of cellulosic fibres with functionalised silanes: Development of surface properties. International Journal of Adhesion and Adhesives, 24, 43-54.
Alemdar, A., \& Sain, M. (2008). Isolation and characterization of nanofibers from agricultural residues-Wheat straw and soy hulls. Bioresource Technology, 99, $1664-1671$.

Ashori, A. (2008). Wood-plastic composites as promising green-composites for automotive industries. Bioresource Technology, 99, 4661-4667.

Belgacem, M. N., \& Gandini, A. (1999). IGC as a tool to characterize dispersive and acid-base properties the surface of fibers and powders. In E. Pfefferkorn (Ed.), Interfacial Phenomena in Chromatography. New York: Marcel Dekker, Inc.

Belgacem, M. N., Blayo, A., \& Gandini, A. (1996). Surface characterization of polysaccharides, lignins, printing ink pigments, and ink fillers by inverse gas chromatography. Journal of Colloid and Interface Science, 182, 431-436.

Buschle-Diller, G., Inglesby, M. K., \& Wu, Y. (2005). Physicochemical properties of chemically and enzymatically modified cellulosic surfaces. Colloids and Surfaces A, 260, 63-70.

Cantergiani, E., \& Benczédi, D. (2002). Use of inverse gas chromatography to characterize cotton fabrics and their interactions with fragrance molecules at controlled relative humidity. Journal of Chromatography A, 969, 101-103.

Cherian, B. M., Pothan, L. A., Nguyen-Chung, T., Menning, G., Kottaisamy, M., \& Thomas, S. (2008). A novel method for the synthesis of cellulose nanofibril whiskers from banana fibers and characterization. Journal of Agricultural and Food Chemistry, 56, 5617-5627.

Condor, J., \& Young, C. (1979). Physicochemical measurement by gas chromatography. Chichester, UK: John Wiley and Sons.

Cordeiro, N., Neto, C. P., Gandini, A., \& Belgacem, M. N. (1995). Characterization of the cork surface by inverse gas chromatography. Journal of Colloid and Interface Science, 174, 246-249.

Cordeiro, N., Gouveia, C., \& Jacob John, M. (2011). Investigation of surface properties of physico-chemically modified natural fibres using inverse gas chromatography. Industrial Crops and Products, 33, 108-115.

Cordeiro, N., Gouveia, C., Moraes, A. G. O., \& Amico, S. C. (2011). Natural fibers characterization by inverse gas chromatography. Carbohydrate Polymers, 84, 110-117.

Cordeiro, N., Mendonça, C., Pothan, L. A., \& Varma, A. (2012). Monitoring surface properties evolution of thermochemically modified cellulose nanofibres from banana pseudo-stem. Carbohydrate Polymers, 88, 125-131.

Cordeiro, N., Ornelas, M., Ashori, A., Sheshmani, S., \& Norouzi, H. (2012). Investigation on the surface properties of chemically modified natural fibers using inverse gas chromatography. Carbohydrate Polymers, 87, 2367-2375.

Gutmann, V. (1978). The donor-acceptor approach to molecular interactions. New York: Plenum Publ. Corp.

Le Troedec, M., Sedan, D., Peyratout, C., Bonnet, J. P., Smith, A., Guinebretiere, R. et al. (2008). Influence of various chemical treatments on the composition and structure of hemp fibres. Composites Part A: Applied Science and Manufacturing, 39, 514-522.

Mills, R. H., Gardner, D. J., \& Wimmer, R. (2008). Inverse gas chromatography for determining the dispersive surface free energy and acid-base interactions of sheet molding compound. Part II. 14 ligno-cellulosic fiber types for possible composite reinforcement. Journal of Applied Polymer Science, 110, 3880-3888.

Mwaikambo, L. Y., \& Ansell, M. P. (2002). Chemical modification of hemp, sisal, jute, and kapok fibers by alkalization. Journal of Applied Polymer Science, 84, 2222-2234.

Newell, H. E., Buckton, G., Butler, D. A., Thielmann, F., \& Williams, D. R. (2001) The use of inverse phase gas chromatography to measure the surface energy of crystalline, amorphous, and recently milled lactose. Pharmaceutical Research, $18,662-666$.

Nourbakhsh, A., \& Ashori, A. (2010). Wood plastic composites from agro-waste materials: Analysis of mechanical properties. Bioresource Technology, 101, 2525-2528.

Panthapulakkal, S., \& Sain, M. (2007). Agro-residue reinforced high-density polyethylene composites: Fiber characterization and analysis of composite properties. Composites Part A: Applied Science and Manufacturing, 38, 1445-1454.

Panthapulakkal, S., Zereshkian, A., \& Sain, M. (2006). Preparation and characterization of wheat straw fibers for reinforcing application in injection molded thermoplastic composites. Bioresource Technology, 97, 265-272.

Papirer, E., Brendle, E., Balard, H., \& Vergelati, C. (2000). Inverse gas chromatography investigation of the surface properties of cellulose. Journal of Adhesion Science and Technology, 14, 321-337.

Ren, X. H., \& Buschle-Diller, G. (2007). Oxidoreductases for modification of linen fibers. Colloids and Surfaces A, 299, 15-21.

Segal, L., Creely, J. J., Martin, A. E., \& Conrad, C. M. (1959). An empirical method for estimating the degree of crystallinity of native cellulose using the X-ray diffractometer. Textile Research Journal, 29, 764-786.

Sheshmani, S., Ashori, A., \& Farhani, F. (2012). Effects of extractives on the performance properties of wood flour-polypropylene composites. Applied Polymer Science, 123, 1563-1567.

Tabarsa, T., Ashori, A., \& Golamzadeh, M. (2011). Evaluation of surface roughness and mechanical properties of particleboard panels made from bagasse. Composites Part B: Engineering 42, 1330-1335.

TAPPI test methods, (2002). Tappi Press: Atlanta, GA.

Wise, E. L., \& Karl, H. L. (1962). Cellulose and hemicellulose. In C. E. Libby (Ed.), Pulp and paper science and technology, pulp. New York, NY, USA: McGraw Book, Co. 